\title{
E QUANDO AS CRIANÇAS COM CINCO ANOS CHEGAM A ESCOLA?
}

\author{
Bianca Santos Chistél \\ Elaine Gracia de Oliveira ${ }^{2}$
}

\section{RESUMO}

Este estudo tem como intenção apresentar o resultado de uma pesquisa desenvolvida de 2015 a 2016, na qual se investigou como acontece a inserção das crianças com 05 anos de idade no ensino fundamental. A investigação realizada em uma escola pública do município de Rolim de Moura caracterizou-se como um estudo de caso e teve como instrumentos de produção de dados a análise documental, a observação em sala de aula, e as entrevistas realizadas com duas professoras do Ciclo Básico de Alfabetização. Fundamentadas em Leite (2011), Kohan (2007), Kramer (2006), Barbosa (2006) entre outros, procuramos discutir neste artigo, sobre a infância e suas singularidades, a partir das implicações da inserção das crianças pequenas no ensino fundamental. As discussões indicam a necessidade de pensarmos a educação da criança, a partir do lugar da infância e da própria criança.

Palavras-chave: Legislação. Infância. Criança. Escola.

\section{AND WHEN CHILDREN WITH FIVE YEARS AROUND SCHOOL}

\section{ABSTRACT}

This study intends to present the result of a research developed from 2015 to 2016, in which investigated how it happens the insertion of children with 5 years of age in elementary school. The research carried out in a public school in the municipality of Rolim de Moura was characterized as a case study and had as instruments of data production the documentary analysis, observation in the classroom, and the interviews conducted with two teachers of the Basic Cycle of Literacy. Foundations in Leite (2011), Kohan (2007), Kramer (2006), Barbosa (2016) among others, we try to discuss in this work, on childhood and its singularities, from the implications of the insertion of young children in teaching fundamental. The discussions indicate the need to think about the education of the child, from the place of childhood and the child itself.

Keywords: Legislation. Childhood. Child. School.

1 Doutora em Educação Matemática (UNESP/Rio Claro). Professora do Departamento de Educação e do Programa de Pós-Graduação em Ensino de Ciências da Natureza, da Universidade Federal de Rondônia, Campus de Rolim de Moura. Orcid iD: https://orcid.org/0000-0002-1962-0256. E-mail: bianca@unir.br

2 Pedagoga, formada pela Universidade Federal de Rondônia, Campus de Rolim de Moura. Professora da Rede Municipal de Corumbá, Mato Grosso do Sul. Orcid iD: https://orcid.org/0000-0002-3706-0619. E-mail: elainegracia_rm@hotmail.com 


\section{Y CUANDO LOS NIÑOS CON CINCO AÑOS LLEGEN LA ESCUELA}

\section{RESUMEN}

Este estudio tiene como intención presentar el resultado de una investigación desarrollada de 2015 a 2016, en la cual se investigó cómo ocurre la inserción de los niños con 5 años de edad en la enseñanza fundamental. La investigación realizada en una escuela pública del municipio de Rolim de Moura se caracterizó como un estudio de caso y tuvo como instrumentos de producción de datos el análisis documental, la observación en el aula y las entrevistas realizadas con dos profesoras del Ciclo Básico de Alfabetización. Basados en Leite (2011), Kohan (2007), Kramer (2006), Barbosa (2006) entre otros, buscamos discutir en este artículo, sobre la infancia y sus singularidades, a partir de las implicaciones de la inserción de los niños pequeños en la enseñanza fundamental. Las discusiones indican la necesidad de pensar la educación del niño, desde el lugar de la infancia y del propio niño.

Palabras clave: Legislación. La infancia. Niño. Escuela.

\section{PRIMEIRAS PALAVRAS}

No ano de 2015, vivemos junto às professoras do Ciclo Básico de Alfabetização, a inserção das crianças de 05 anos de idade no ensino fundamental, devido ao sancionamento de uma resolução estadual. Isso provocou muitas indagações: A quem serve a inserção das crianças pequenas no ensino fundamental? A que custo isso acontece? Como organizar um espaço pensado para crianças maiores, em um espaço para crianças menores? Quais atividades propor e como propor, considerando que o desejo das crianças é brincar? Que escola é essa que recebe as crianças pequenas? Como articular a proposta curricular aos desejos das crianças (brincar, falar, movimentar, inventar etc.)? Como escolarizar sem subtrair a infância? Essas e tantas outras inquietações mobilizaram nossa intenção de pesquisa junto às professoras e às crianças do primeiro ano de escolarização.

Assim, este artigo apresenta o resultado de uma pesquisa desenvolvida durante 02 anos em uma escola pública estadual, em Rolim de Moura - RO, com duas professoras ${ }^{3}$ e crianças do Ciclo Básico de Aprendizagem - CBA, na qual objetivou investigar as implicações da inserção das crianças com 05 anos no ensino fundamental. Nessa investigação caracterizada como

\footnotetext{
${ }^{3}$. Os nomes das professoras e das crianças que aparecem no artigo são fictícios.
} 
estudo de caso, utilizamos como instrumentos para produção dos dados: entrevista com duas professoras do CBA; observação em sala de aula durante dois anos (2015 e 20164); e análise documental (caderno de registro docente e caderno de campo de uma das pesquisadoras).

O estudo indicou que a inserção das crianças com 05 anos no ensino fundamental provoca a escola de maneira geral, e as professoras de modo mais particular, a pensarem na organização do tempo e espaço escolar, nos materiais pedagógicos, nas atividades didáticas propostas, no fazer das crianças no espaço da sala de aula e fora dela e na formação docente de quem lida com a infância. Dessa forma, o texto que segue inicialmente aborda os aportes legais referentes à política pública de reorganização do ensino fundamental de 08 para 09 anos juntamente com a homologação da nova liminar da idade corte. Nas sessões seguintes, apresenta e discute sobre a inserção das crianças com 05 anos no ensino fundamental; a formação docente e o trabalho com as crianças pequenas, bem como as mudanças na prática docente provocada pela entrada destas crianças na escola.

\section{O QUE DIZ A LEGISLAÇÃO SOBRE A IDADE DE INSERÇÃO DA CRIANÇA NO ENSINO FUNDAMENTAL}

A organização da educação brasileira passou por uma série de reestruturação a partir do reconhecimento do direito à educação das crianças de 0 a 06 anos de idade expresso na Constituição Federal de 1988 (CF/88) e que foi regulamentada pela Lei de Diretrizes e Bases da Educação Nacional de 1996 (LDB 9394/96). A LDB abre espaço para a consolidação de uma identidade da educação infantil, colocando essa como primeira etapa da educação básica.

Dentre as mudanças ocorridas até então, o ensino fundamental - EF de 09 anos se tornou uma meta a ser alcançada pelos sistemas de ensino de todo o país. Essa nova organização foi possível por meio da Lei Federal $n^{\circ}$ 11.114, de 2005, que tornou obrigatório a entrada das crianças com 06 anos na educação básica. Aliado a essa, em 2006, a Lei Federal n 11. 274

${ }^{4}$. Uma das pesquisadoras foi bolsista do Programa de Bolsas de Iniciação à Docência PIBID, Subprojeto Pedagogia, UNIR/Rolim de Moura, durante 04 anos (2014 a 2016). 
ampliou o ensino fundamental de 08 para 09 anos. A LDB previa "O ensino fundamental, com duração mínima de oito anos, obrigatório e gratuito na escola pública [...]" (BRASIL, 1996, Art. 32). A mesma lei dispunha sobre a idade para o ingresso nessa etapa da educação básica, "é dever dos pais ou responsáveis efetuar a matrícula dos menores, a partir dos sete anos de idade, no ensino fundamental" (BRASIL, 1996, Art. $6^{\circ}$ ). Os referidos artigos sofreram mudanças em sua disposição ao longo dos anos.

A Lei 10.172 de 09/01/2001, que aprovou o Plano Nacional de Educação - PNE (2001-2011) instituiu como objetivo e meta do ensino fundamental "Ampliar para nove anos a duração do ensino fundamental obrigatório com início aos seis anos de idade, à medida que for sendo universalizado o atendimento na faixa de 7 a 14 anos". Assim, o PNE (20012011 ) estabeleceu a ampliação do ensino fundamental de 08 para 09 anos, com ingresso aos 06 anos de idade. A iniciativa para o cumprimento desta meta, contudo, dependeria da iniciativa da União. Essas discussões começaram a aflorar a partir de 2004 com debates nacionais.

O novo PNE Lei $n^{\circ}$ 13.005, aprovado em 25 de junho de 2014, com validade até 2024, estabeleceu em sua meta de número 02, "universalizar o ensino fundamental de nove anos para toda a população de seis a quatorze anos e garantir que, pelo menos, noventa e cinco por cento dos alunos concluam essa etapa na idade recomendada, até o último ano de vigência deste PNE" (BRASIL, 2014, p. 33).

Dessa forma, a Lei Federal $n^{\circ} 11.114$, de maio de 2005 alterou os artigos. $6^{\circ}, 30,32$ e 87 da LDB, com o objetivo de atender ao Plano Nacional de Educação. Assim, ficou instituído que "é dever dos pais ou responsáveis efetuar a matrícula dos menores, a partir dos seis anos de idade, no ensino fundamental" (BRASIL, 2005, Art. 6\%). Concomitante a isso, a LDB foi novamente alterada em seus artigos 29, 30, 32 e 87, dispondo sobre a duração de 09 anos para o ensino fundamental com matrícula obrigatória a partir dos 06 anos de idade. Tais leis encontraram respaldo legal na Constituição Federal de 1988, em seu artigo 208, na LDB e no PNE Lei Federal no 10.172 (2001-2011). 
O Ministério de Educação - MEC ao estabelecer a ampliação do ensino fundamental de 09 anos com ingresso aos 06 anos de idade objetiva garantir às crianças nessa faixa etária a entrada mais cedo, e conclusão do ensino fundamental aos 14 anos, pensando assim, em proporcionar qualidade na educação. Dessa maneira, o Parecer CNE CEB ${ }^{5} n^{\circ} 4$, de 20/02/2008 orienta sobre os três anos iniciais do ensino fundamental de 09 anos, com ingresso aos 06 anos de idade. Por meio deste Parecer, 0 CNE/CEB (BRASIL, 2008, p. 02) estabelece 12 procedimentos pedagógicos recomendados para a faixa etária dos 06 aos 08 anos de idade, dos quais destacaremos os 04 primeiros:

1 - O Ensino Fundamental ampliado para nove anos de duração é um novo Ensino Fundamental, que exige um projeto políticopedagógico próprio para ser desenvolvido em cada escola.

2 - O Ensino Fundamental de nove anos, de matrícula obrigatória para crianças a partir dos seis anos - completos ou a completar até o início do ano letivo - deverá ser adotado por todos os sistemas de ensino, até o ano letivo de 2010, o que significa dizer que deverá estar planejado e organizado até 2009, para que ocorra sua implementação no ano seguinte.

3 - A organização do Ensino Fundamental com nove anos de duração supõe, por sua vez, a reorganização da Educação Infantil, particularmente da Pré-Escola, destinada, agora, a crianças de 4 e 5 anos de idade, devendo ter assegurada a sua própria identidade. 4 - O antigo terceiro período da Pré-Escola não pode se confundir com o primeiro ano do Ensino Fundamental, pois esse primeiro ano é agora parte integrante de um ciclo de três anos de duração, que poderíamos denominar de "ciclo da infância".

Tendo em vista as leis já citadas, a Resolução CNE/CEB nº 01, de 14 de janeiro de 2010 (BRASIL, 2010, p. 2) define diretrizes operacionais para a implantação do ensino fundamental de 09 anos pontuando que:

Art. $2^{\circ}$ Para $\circ$ ingresso no primeiro ano do Ensino Fundamental, a criança deverá ter 6 (seis) anos de idade completos até o dia 31 de março do ano em que ocorrer a matrícula.

Art. $3^{\circ}$ As crianças que completarem 6 (seis) anos de idade após a data definida no artigo $2^{\circ}$ deverão ser matriculadas na Pré-Escola.

Nesses termos a Resolução CNE/ CEB n 06, de 20 de outubro de 2010 define diretrizes operacionais para a matrícula no ensino fundamental e para

5. Câmaras de Educação Básica-CEB. 
a educação infantil dispondo em seus artigos $3^{\circ}$ e $4^{\circ}$ que "Para o ingresso no primeiro ano do Ensino Fundamental, a criança deverá ter idade de 6 (seis) anos completos até o dia 31 de março do ano em que ocorrer a matrícula". Art. $4^{\circ}$ As crianças que completarem 06 anos de idade após a data definida no artigo $3^{\circ}$ deverão ser matriculadas na Pré-Escola.

Para que 0 ensino fundamental de 09 anos tenha resultado, juntamente com o ingresso das crianças com 06 anos de idade nessa etapa da educação básica, Saveli (2008, p. 69). Expõe que:

[...] exige das secretarias de educação investimentos na formação de professores, tanto a formação básica quanto a continuada; na organização da escola em ciclos de aprendizagem; na organização, ampliação e adequação dos espaços físicos, materiais e pedagógicos. Exige, ainda, investir na melhoria das condições de trabalho dos professores, revendo carga horária, número de alunos por classe, sua formação permanente, entre outras tantas questões.

O ingresso da criança de 06 anos como uma política pública de governo deve vir acompanhado de uma reorganização do ensino fundamental que contemple o projeto político pedagógico, currículo, formação de professores, além de repensar o espaço físico da escola. Saveli (2008, p. 69) pontua que "a inclusão das crianças de seis anos na escolaridade obrigatória resgata um direito de cidadania, uma vez que permite a uma parcela maior da população se beneficiar de um direito que antes era de poucos".

Contudo, Orlandi e Lima (2015, p. 128) destacam outro olhar sobre a organização do ensino fundamental de 09 anos, "[...] apesar de a legislação assegurar a todas as crianças um maior tempo de convívio escolar esse aumento não tem significado efetivamente uma qualificação do processo de ensino-aprendizagem". A problemática não se encontra na expansão do ensino fundamental de 08 para 09 anos, mas sim nas condições estruturais, pedagógicas e curriculares que encontramos na realidade das escolas da rede pública brasileira, e não muito diferente, às escolas particulares.

A inserção das crianças de 06 anos de idade no ensino fundamental com matrícula até o dia 31 de março vem sendo passiva de críticas, haja vista que houve uma reorganização no sistema educacional em curto prazo 
e as escolas não têm conseguido se adequar, seja pedagógica ou estruturalmente.

A Secretaria do Estado de Rondônia, acolhendo os referidos atos normativos que dispõe sobre a nova duração do ensino fundamental, com matrícula obrigatória, a partir dos 06 anos de idade, editou a Resolução Estadual $n^{\circ}$ 824/2010, CEE $6 /$ RO de 06 de dezembro de 2010 que fixa normas para a matrícula na educação infantil e no ensino fundamental no sistema estadual de ensino a partir do ano letivo de 2011.

A Resolução no 824/2010/CEE/RO em seu artigo $5^{\circ}$ dispõe que para o ingresso no primeiro ano do ensino fundamental, a criança deverá ter a idade de 06 anos completos até o dia 31 de março do ano em que ocorrer a matrícula. Entretanto, antes mesmo que as instituições se adequassem conforme as necessidades das crianças, o Juiz Federal da $2^{a}$ Vara/PE Dr. Claudio Kitner por meio dos autos do processo no 0013466-31.2011.4.05.8300 (RECIFE, 2011, p. 04) liminar da idade corte veio revogar:

[...] os termos da decisão fls. 30, pelo que determino sejam suspensas, em sede liminar, as disposições das Resoluções nº 01, de 14/01/2010 e de $n^{\circ} 06$, de 20/10/2010 e outras normas que a elas se seguiram de igual conteúdo, no que tange à proibição de ingresso no ensino fundamental de crianças menores de 06 (seis) anos de idade de 31 de março do ano letivo a ser cursado, de modo a permitir a regular matrícula desses educandos nas instituições escolares.

A liminar assinada pelo Juiz Federal de Pernambuco abriu precedente para que outros estados aderissem à mesma decisão. Dessa forma, o estado de Rondônia por meio dos autos do processo n 11677-27.2013.4.01.4100, liminar da idade corte considera da mesma forma, que as Resoluções supracitadas "impõem tratamento desigual em relação àquelas crianças que completem 06 anos de idade após 31 de março e que tenham condições de ingressar no primeiro ano do Ensino Fundamental" (RONDÔNIA, 2013, p. 01). Além disso, pontua que as "Resoluções do Conselho Nacional de Educação - CNE implicam violação do art. 208, V, da Constituição Federal ou do princípio da isonomia." (RONDÔNIA, 2013, p. 02). Usou-se também como respaldo a lacuna deixada pela Lei de

\footnotetext{
${ }^{6}$. Conselho Estadual de Educação.
} 
Diretrizes e Bases da Educação Nacional 9.394/1996 - LDB, a qual estabelece que as crianças ingressem no ensino fundamental no ano que completem 06 anos de idade, porém, o ato normativo não impôs a respeito da data para o ingresso no ano que deva ocorrer à matrícula da criança.

Vindo assim, os autos do processo $n^{\circ}$ 11677-27.2013.4.01.4100 liminar da idade corte "suspender a Resolução CNE/CEB 01/2010, art. 2, a Resolução CNE/CEB n $n^{\circ}$ 06/2010, artigos $3^{\circ}$ e $4^{\circ}$, a Resolução Estadual 824/2010, artigos $3^{\circ}$ e 5" (RONDÔNIA, 2013, p. 13), estabelecendo que a criança deva ter entre 04 e 06 anos de idade a completar até o dia 31 de dezembro do ano da matrícula para a inserção na pré-escola e ensino fundamental. Isto é, a determinação legal trouxe para as instituições de ensino outra realidade, uma vez que várias crianças completam 06 anos de idade, a partir do segundo semestre do ano, tendo ainda algumas que o fazem após o final do ano letivo.

Dentro desse aparato de leis e resoluções que regulamentam o ensino fundamental de 09 anos, e a inserção da criança com 06 anos, a liminar da nova idade corte de 2013, assinada pelo Juiz Federal Dimis da Costa Braga, suspende as Resoluções supracitadas, dispondo que para o ingresso no ensino fundamental a criança deverá ter idade de 06 anos a completar até o dia 31 de dezembro do ano em que ocorrer a matrícula. Alguns Conselhos Estaduais de Educação - CEE que receberam judicialmente a revogação da data corte de matricula no ensino fundamental, de 31 de março para 31 de dezembro do ano em que ocorrer a matrícula conseguiram a revogação da liminar, por exemplo, Paraná e Pará.

Observamos no processo judicial anteriormente citado que os embasamentos para as decisões judiciais que suspendem as resoluções nacional e estadual (RO), fundamentam-se, principalmente, na legislação vigente, na qual se destacam os seguintes argumentos: a LDB 9394/96, no art., 32 (com a alteração da Lei 11.274/2006) não impõe restrição de data para o ingresso que deva ocorrer a matrícula da criança no ensino fundamental; a restrição etária, de acordo com o argumento, afronta o desenvolvimento sadio e harmonioso da criança, norma essa estabelecida 
no Estatuto da Criança e dos Adolescentes (Lei 8069/90, art. $7^{\circ}$ ); ampara-se ainda na Declaração Universal dos Direitos do Homem (artigo XXIV) o acesso igualitário a educação.

Embora haja um princípio argumentativo no processo citado, de que o Estado deve assegurar a criança acesso aos níveis mais levados do ensino, da pesquisa e da criação artística, segundo a capacidade de cada uma, o direito à educação volta-se a estar matriculada no ensino fundamental. Ou seja, o direito a educação da criança até os 05 anos de frequentar a educação infantil, conforme prevê a mesma Lei (LDB 9394/96, redação alterada pela Lei $12.796 / 2013)$ não é discutido, muito menos o direito das crianças ao brincar, como forma particular de expressão, de pensamento, de interação e de comunicação infantil, visto que, a partir da entrada obrigatória no ensino fundamental, as crianças são submetidas à organização semelhante ao mundo do trabalho com controle de tempos e de espaços definidos.

Parece-nos que, primeiro a decisão é tomada da ordem do direito pelo direito e não leva em conta a criança e a própria infância. Fundamentam-se nas leis, normatizações resoluções, declarações universais, mas na verdade, a criança que deveria ser o centro das discussões, não se faz presente, a não ser pela palavra criança. Segundo impera uma lógica que se distancia cada vez mais das necessidades das crianças pequenas, um modo de pensar que subtrai a infância das crianças, conduzindo-as cada vez mais cedo ao modo adulto de pensar e viver e mundo.

Assim, sabemos que a organização da escola de ensino fundamental tem sido pensada, tanto em seus aspectos estruturais e pedagógicos para atender crianças maiores. A obrigatoriedade da matrícula no ensino fundamental estava destinada às crianças com 07 anos, mesmo com a mudança de idade para 06 anos ou mesmo 05 anos, observamos que a escola continua a mesma, toda sua estrutura pensada a partir do tempo, espaço e modos de vida do adulto, na subtração dos corpos, no pensamento anestesiado, no entorpecimento da rotina e da vida. Tornando o debate ainda mais discutível, as crianças que hoje frequentam as salas de aula do primeiro ano do ensino fundamental há pouco tempo atrás estariam 
inseridas na educação infantil.

\section{AS CRIANÇAS COM 05 ANOS ESTÃO NO ENSINO FUNDAMENTAL E AGORA?}

Dentro de uma nova organização educacional em que os professores se deparam com um novo público, o qual tem características específicas a sua idade, sendo essas diferentes do que estavam habituados a trabalhar, naturalmente, surgem muitos desafios ao trabalho docente. A nova legislação para o ensino fundamental que define a data corte de matrícula para o dia 31 de dezembro exige mudanças em todo o sistema de ensino, que envolve uma nova organização e estruturação das unidades escolares no plano político e pedagógico.

Dessa forma, as unidades escolares necessitam de uma mudança extremamente radical, para que a infância, de alguma maneira, seja respeitada. Observa-se, porém, que as adequações necessárias não vêm acontecendo. Tanto a educação infantil quanto o ensino fundamental que passa por reestruturações como a mudança na data corte, precisam pensar a infância em um contexto mais amplo em que seja respeitado não somente o direito do acesso à educação, mas sim, o acesso a diferentes vivências, novas possibilidades levando em conta sua própria identidade. As professoras entrevistadas nos mostraram que essas diferenças não estão sendo respeitadas, uma vez que a escola onde ocorreu a pesquisa não adequou, por exemplo, o mobiliário indicado para esta faixa etária ao receber as crianças, como afirma a professora Eva (Entrevista, 08/03/2016):

[...] se a gente for observar têm muitas crianças que não alcançam o pé no chão, apesar de serem cadeiras menores em relação às antigas. As cadeiras e carteiras são pequenas para os alunos que usam a sala no contraturno, porém o sofrimento não é só para os alunos do $6^{\circ}$ ou $7^{\circ}$ ano, o sofrimento também é para os alunos de 05 anos que ficam com os pezinhos pendurados. Têm pais que fazem uma adaptação, trazem um banquinho para o filho colocar o pé porque o fato de ficar com os pés pendurados já estava causando certo problema na coluna do aluno. Então, está adequado? Não está. Nem para os que estudam no matutino e, nem para os que estudam no vespertino.

Tais mudanças, como se pode ver, mexem com toda a escola, colocando uma série de problemas, tanto para as crianças pequenas 
inseridas no ensino fundamental quanto para os alunos maiores do contraturno. Entretanto, ter crianças menores na alfabetização em um turno e outras maiores nos anos finais do ensino fundamental no período oposto traz outras implicações para se trabalhar com as crianças pequenas, pois impossibilita uma prática adequada a elas. Em sua fala a professora Eva (Entrevista, 08/03/2016) nos diz:

\begin{abstract}
Nós já falamos do mobiliário, cadeira e carteira, mas nesse espaço para alunos de 05 anos teria que ter outras coisas atrativas: 0 cantinho da imaginação; o cantinho da leitura; o cantinho da pintura; da arte, e isso é impossível de acontecer nesse espaço. Eu ainda garanto o canto da leitura, mas seria interessante ter outros cantos para que as crianças não ficassem ansiosas e ociosas nesse espaço [...] Não é que não se pode ter, não tem condições. Eu tenho dois armários, nesses armários não cabe todo o material para suprir esses cantos. Garanto o cantinho da leitura, mas todos os dias eu tenho que tirar todos os livros e guardar nos armários.
\end{abstract}

Isso ocorre, entre outros fatores, porque não existe espaço apropriado e exclusivo para as crianças que têm entre 05 e 06 anos de idade. Ainda que a educação infantil não tenha se mostrado em nosso município como espaço físico ideal a receber as crianças menores, ela possibilita aos pequenos um pouco mais de liberdade e de movimento. Ou seja, no ensino fundamental as crianças estão sendo impedidas de movimentar em espaços-tempos que as levem a vivenciar práticas, experimentar, experenciar, naturalmente porções do mundo. Tem se roubado da criança seu tempo, quiçá sua infância como indica Leal (2006, p. 247):

[...] não posso deixar de pensar sobre como a Escola trata a infância, sobre como a escola não a escuta, portanto desqualifica suas ações e atitudes. Adultizamos muito cedo nossas crianças e matamos a infância de cada uma. [...] penso, ainda, nos silêncios impostos, nas escolhas determinadas, na direção adultizada do mundo; repetem os mesmos gestos, fazem os mesmos exercícios, brincam as mesmas brincadeiras e são obrigadas a viver um espaço-tempo que não é o que escolheram.

Como afirma Leal, a escola não respeita o tempo da criança, e a sociedade caminha na mesma direção, de conceber as pequenas como seres adultos alheios de qualquer especificidade. A infância é uma condição humana, na qual todos, um dia, encontraram-se. A criança percebe o 
mundo ao seu modo, ao seu tempo de acordo com sua realidade, sua condição existencial. Kohan (2007, p. 86) afirma que "[...] o tempo da vida não é apenas questão de movimento numerado e que esse outro modo de ser temporal parece com o que uma criança faz. Se uma lógica temporal segue os números, outra brinca com os números".

Kohan (2007) coloca que a infância não é apenas uma etapa da vida humana, ela tem que ser marcada por outra relação: o movimento. 0 tempo da infância não é linear, não é codificado, ou seja, é um tempo intensivo, aiônico, como "sugere Heráclito" (KOHAN, 2007, p. 87). Em outras palavras "a infância não é apenas uma questão cronológica: ela é uma condição da experiência" (2007, p. 26).

O tempo outro da criança pode ser observado como uma das implicações ocasionadas pela entrada delas com 05 anos de idade no ensino fundamental. No que diz respeito a isso, notamos por meio das entrevistas, que as professoras tiveram que se adequar ao tempo, ao ritmo, às peculiaridades das crianças em seus fazeres pedagógicos. A professora Karen (Entrevista, 03/03/2016) relata:

\begin{abstract}
Olha, eu tive aquele cuidado de estar sempre trabalhando praticamente individualmente com eles. Não tem outra forma de trabalhar, você tem que passar a atividade e estar observando se cada um está acompanhando direitinho. Porque a dificuldade deles é na atenção. Passo a atividade, explico, vou para o quadro, desenho no quadro, mostro onde tem que fazer e às vezes eles se perdem. Hoje mesmo estavam fazendo uma tarefinha de subtração, e na hora que eles diminuem, fazem bolinhas para diminuir, contar, quando voltam para o cálculo já se perderam, não sabe qual deles estava resolvendo. Então, tem que ser bem observado, bem devagarinho com bastante atenção, muita cobrança, porque eles se dispersam facilmente.
\end{abstract}

A fala da professora nos apresenta outra questão: o quão sofrido, exaustivo é para as crianças serem inseridas, em um sistema no qual são obrigadas a ficar quatro horas com um pequeno intervalo, presas em uma sala, por vezes, extremamente pequenas, cercadas por quatro paredes e muros que as impedem de visualizar o contexto externo à escola, forçadas a ficarem sentadas enfileiradas e de preferência caladas. Essa disciplina do corpo é uma mudança muito brusca, pois, em um ano, a criança está no 
parquinho brincando se relacionando de forma dinâmica com colegas, aprendendo pelo movimento do corpo. No ano seguinte, ao ingressar no ensino fundamental, espera-se dela passividade, ou seja, a criança tem que aprender parada, sem movimentar-se.

Nesse aspecto, vislumbramos a concepção de infância que a escola tem, a qual em sua função social dentro da sociedade capitalista serve fielmente ao mercado, isto é, atropela-se a infância cada vez mais cedo. Sobre o diálogo que deveria haver entre educação infantil e ensino fundamental para a inserção da criança nesta etapa escolar, o Ministério da Educação (BRASIL, 2006, p. 21) orienta que:

[...] não pode representar uma ruptura com o processo anterior, vivido pelas crianças em casa ou na instituição de educação infantil, mas sim uma forma de dar continuidade às suas experiências anteriores para que elas, gradativamente, sistematizem os conhecimentos sobre a língua escrita.

A partir da análise documental observamos que a escola da forma como tem trabalhado impõe às crianças um rompimento com as experiências vividas na educação infantil, podendo ocasionar impactos negativos no processo de ensino e aprendizagem, Kramer (2006, p. 7) pontua a importância da articulação entre educação infantil e ensino fundamental:

Embora educação infantil e ensino fundamental sejam frequentemente separados, do ponto de vista da criança, não há fragmentação. Os adultos e as instituições que muitas vezes opõem educação infantil e ensino fundamental, deixando de fora o que seria capaz de articulá-los: a experiência com a cultura.

Tal situação evidencia-se no caderno de campo, "Quanto a isso retomo a discussão do relatório anterior, penso que a escola atual não tem condição de atender corretamente os alunos, uma vez que as crianças são submetidas à escola aos cinco anos de idade, porém o currículo continua o mesmo" (OLIVEIRA, caderno de campo, 03/2016).

Esse registro vem de encontro à fala da professora Eva, quando perguntado a ela se essa mudança educacional foi incorporada ao currículo da escola, a saber, ela disse: "Não. Quando a gente vai analisar o 
currículo a gente vê que é o mesmo currículo do aluno de 07 anos, sem alteração". (Entrevista, 08/03/2016). É Sabido que deve existir uma articulação e continuidade entre educação infantil e ensino fundamental, que tal ruptura não lhes favorece no processo de ensino e aprendizagem, nesse viés Barbosa colabora (2006, p. 37):

Há uma expectativa e uma pressão social bastante acentuadas de que ela seja alfabetizada. A família espera, a professora sente-se incompetente se não consegue alfabetizar e as crianças que não realizam o processo sentem-se fracassadas e incapazes. Tal fato aponta que colocar as crianças de camadas populares na escola de ensino fundamental aos seis anos sem uma proposta pedagógica adequada significa apenas antecipar o fracasso escolar.

Trabalhar com essas crianças, não significa fazer um simples ajuste no conteúdo, é preciso mudanças que inovem pensando nas reais necessidades das crianças, não há como trabalhar o mesmo currículo ou as mesmas práticas que antes eram trabalhadas com as crianças de 07 , ou mesmo 06 anos. Considerando as necessidades que acompanham as crianças pequenas, faz-se imprescindível oferecer a elas possibilidades várias de aprendizagem, mudar o foco da prática pedagógica, desenvolver um processo de alfabetização que dialogue com a necessidade primeira da criança: o brincar.

Ao interrogar a professora Karen sobre quais foram as principais diferenças entre o planejamento de suas aulas para as turmas do antigo primeiro ano em relação ao primeiro ano atual, obtivemos a seguinte resposta (Entrevista, 03/03/2016):

O antigo com 06 anos também foi uma surpresa para a gente que trabalhava só com alunos de 07 anos de idade, aí vieram os de 06 e nós ficamos pensando se daríamos conta. Mas foi muito mais leve para eles e para mim do que com os de 05 anos. Os de 05 anos me suaram bastante (risos)..., me sugou muito porque eles querem mais atenção. São 25 alunos e uma professora dentro da sala de aula, é muito trabalhoso porque tenho que auxiliar um e têm outros conversando, bagunçando. Tenho que estar passando atividade para que eles não dispersem e, eu não posso deixar para trás a tarefa. Um ou dois alunos, às vezes não dou conta, tenho que estar repassando de carteira em carteira, aí vira aquela bagunça. É difícil controlar essa turma de 05 anos. Com os outros (06 anos) eu colocava a tarefa no quadro e eles já queriam fazer a letra cursiva, era animador porque eles aceitavam mais. Esses de 05 anos, eu tive 
que trabalhar o ano todo com a letra palito, não teve aquela vontade de fazer, tive muito mais trabalho.

Vemos assim, que as crianças apresentam resistência quando expostas a novos padrões de organização do ensino fundamental. Interessa-nos expor que tais mudanças seguem a Lei ao que diz respeito à idade corte, porém, não se atendem as orientações previstas pelo próprio Ministério da Educação, quando indica que "não se trata de transferir para as crianças de seis anos os conteúdos e atividades da tradicional primeira série, mas de conceber uma nova estrutura de organização dos conteúdos em um ensino fundamental de nove anos, considerando o perfil dos alunos" (BRASIL, 2004, p. 17).

Entendemos que, a reorganização do ensino fundamental não versa apenas em pensar um novo currículo, mas também, os espaços e ambientes escolares, bem como o tempo. Observamos que isso não aconteceu na escola pesquisada. Porém, nos parece que essa não seja uma realidade isolada, visto que as demais escolas públicas do município de Rolim de Moura (estaduais e municipais) apresentam a mesma realidade: currículo, as carteiras e cadeiras, o espaço físico são os mesmos não importando a idade que a criança é inserida no ensino fundamental. Entretanto, observamos que algumas professoras preocuparam-se ainda mais ao serem informadas da chegada das crianças com 05 anos à escola, mesmo diante da naturalização dessa inserção, como pontua a professora Eva (Entrevista, 08/03/2016):

Tivemos então uma reunião com a supervisora e eu disse: Nossa! Vai ser difícil trabalhar com esses alunos, porque nós não temos nenhum espaço agradável para essas crianças, o que tem aqui que chamaria atenção desses alunos? Falei: tudo bem, esta sendo inserido com 06 anos, hoje com 05 anos, mas cadê o playground? Cadê a quadra de areia para essas crianças? Sabe o que aconteceu? Todos olharam para minha cara e começaram a dar risada, alguns falaram: "você esta sonhando?" "Falei: não é sonho não, é necessidade, os alunos precisam disso". Hoje já passou um tempo, chegaram à escola com 05 anos e não temos playground, não temos quadra de areia, não temos um espaço que possamos dizer: nesse espaço, as crianças de 05 anos vão parar para brincar.

Diante do exposto, as professoras entrevistadas narraram outra 
situação que está associada ao tempo, trata-se da alteração de seus planejamentos. Quando interrogadas se houve modificação em seus planejamentos de aula, a professora Karen (Entrevista, 03/03/2016) declara que:

Foram mais atividades impressas, muito mais do que com os alunos de 06 anos, tive que usar mais a atividade impressa do que o quadro, o quadro ficou um pouco de lado. Esse ano estou usando mais o quadro, mas ainda tem muita atividade impressa para eles fazerem.

Podemos dizer ainda, que a professora Karen ao olhar para as crianças de 05 anos percebe suas necessidades quanto ao espaço, ao tempo, compreende que atuar com tais crianças exige-se um modo diferenciado, mas encontrava dificuldades em propor atividades de modo diferente do que habitualmente faz/fazia há anos. Não se trata, portanto, de não querer fazer, mas sim, de não saber como modificar sua prática vislumbrando, por exemplo, a aprendizagem a partir da utilização de materiais concretos, brincar, entre outros. As falas das professoras e suas práticas nos possibilita também abordar, sob o olhar delas, a formação do professor da infância.

\section{FORMAÇÃO DOCENTE: o trabalho com as crianças pequenas}

Quando nos debruçamos sobre o histórico das políticas públicas educacionais, observamos pelo menos desde a implantação da LDB 9394/96, que ele tem sido marcado pelo investimento na formação de professores. Mesmo que haja críticas em relação ao tipo de formação propiciada e também ao grande número de documentos orientadores, como aponta Arelaro (2005), ainda assim, há certa qualificação do profissional que trabalha com crianças. São nesses espaços, mesmos que eventuais, esporádicos, precários e "longe de garantir tempo e espaço para a qualificação necessária ao trabalho com crianças" como destaca Kramer (2006, p. 806), que professores ainda podem discutir sobre suas experiências educativas, seus medos e anseios.

Entretanto, a inserção das crianças de 05 anos no ensino fundamental 
(e também as de 6 anos) em Rondônia, veio marcada por nenhuma oportunidade de formação oferecida aos professores, como observamos na fala das professoras, ao serem questionadas sobre isso: "Nenhuma. Veio assim de presente mesmo, e foi um desafio. Foi não, está sendo um desafio". (Entrevista, 03/03/2016). Condizente a isso, a professora Eva (Entrevista, 08/03/2016), pontua que não houve formação de professores para a inserção das crianças de 05 anos, afirmando que "Não, não teve. Não teve para a inserção de 05 anos, nem para a inserção de 06 anos".

A mudança na idade corte para 0 dia 31 de dezembro afeta diretamente $\mathrm{o}$ trabalho dos professores que anteriormente à reorganização do ensino fundamental atuavam com crianças de 07 anos, em seguida as de 06 e agora as pequenas de 05 anos de idade como reitera a professora (Entrevista, 08/03/2016) entrevistada:

\begin{abstract}
Quando eu comecei a trabalhar na escola a $1^{a}$ série era com alunos de 07 anos. Então, eu trabalhei primeiro com os alunos de 07 anos e, lembro que na época estava eu, a Maria e a Joana na alfabetização da $1^{a}$ série. Depois quando nós chegamos, eles (coordenação pedagógica, direção) falaram: "os alunos agora são de 06 anos no $1^{\circ}$ ano." "Então, teve preparação para recebê-los"? Não teve. Teve preparação quando nós já estávamos trabalhando com os alunos porque daí surge o PROFA, surgem alguns cursos referentes a isso, alguns estudos, mas dizer que o professor foi preparado para receber esses alunos, não foi [...] E com os de 05 anos não teve, porque tem o PNAIC, mas não é algo referente à inserção de alunos com 05 anos de idade.
\end{abstract}

Assim, fica nítido que as professoras não tiveram nenhum tipo de informação, ou formação própria para trabalhar com as crianças de 06 anos de idade, tão pouco para com as de 05 anos no primeiro ano do ensino fundamental. Obviamente, os professores de modo geral se defrontaram com uma realidade desafiadora, que diz respeito, não somente a uma mudança no ordenamento jurídico, mas implica em toda a organização escolar, que envolve pontualmente suas atividades pedagógicas.

Além disso, os professores não foram inseridos em um debate amplo a nível nacional sobre tais mudanças na idade corte, ou seja, o estado não ouviu aqueles que mais compreendem as necessidades educacionais. Do 
mesmo modo, há evidências que a escola onde se deu a pesquisa não reuniu a equipe escolar para informar as mudanças ocorridas, como percebido quando a professora Karen (Entrevista, 03/03/2016) coloca:

Não me inteiro muito dos assuntos da coordenação, direção, porque me envolvo mais com a sala de aula. Fiquei sabendo que foi um engano a turma de 05 anos, mas que não podiam (a direção) mais voltar atrás porque as crianças já estavam matriculadas.

A partir de sua declaração vislumbra-se que a professora entrevistada esteve à margem das mudanças legais da idade corte para matrícula no ensino fundamental. Ou seja, a professora termina o ano letivo pensando que as crianças que receberá no ano seguinte têm 06 ou quase 06 anos, porém, quando tomou ciência as crianças de 05 anos já formavam sua próxima turma a trabalhar de forma repentina.

Diante disso, percebemos que a escola não teve tempo para se organizar para receber as crianças com 05 anos de idade em razão de a liminar da idade corte assinada pelo juiz Federal do estado de Rondônia não ter previsto tempo hábil de adaptação das escolas e professoras, bem como do currículo. Isto é, a Lei foi sancionada, impondo muitas outras coisas à escola e que não foram pensadas por quem a legislou.

A atual conjectura educacional pressupõe outra forma de conceber a escola, um redirecionamento do fazer pedagógico, uma nova forma de pensar a organização do espaço e do tempo escolar. Tais questões desembocam em um olhar distinto daquele que corriqueiramente tem se lançado para a criança como nos aponta Lira et al (2011, p. 159):

[...] é um grande desafio para os professores trabalharem de maneira lúdica no $1^{\circ}$ ano do Ensino Fundamental, uma vez que isso exige repensar sobre suas práticas e investimentos em sua formação, pois sabemos que é necessário reavaliar várias posturas. Além disso, o espaço físico e os materiais precisam ser apropriados para o trabalho com crianças pequenas, de maneira a valorizar sua autonomia e proporcionar seu desenvolvimento.

Embora não tenham tido formação alguma para lidar com esse novo desafio, algumas docentes vão mudando suas práticas por sentirem as 
necessidades impostas pelas crianças, outros se mostram resistentes, ocorrendo assim um movimento reverso do indicado na Lei, isto é, as crianças são forçadas a se adequarem as práticas vigentes na escolarização da infância. Uma das professoras (Entrevista, 08/03/2016) entrevistadas afirmar que:

[...] às vezes a gente sente insegurança ou sente até... (pausa) como eu posso dizer? Subestimo os alunos, porque às vezes a gente acaba subestimando eles: será que o aluno vai conseguir? Será que ele dará conta de fazer isso? E aos poucos dá para perceber que sabendo encaminhar o processo de aprendizagem eles devolvem sim, conseguem aprender. Mas a insegurança foi muito grande.

Essa insegurança demonstrada pela professora pode ser, entre outros motivos, pela ausência de formação para os professores trabalharem com as crianças de 05 anos, sabe-se que as mudanças ocorridas supõem uma nova forma de pensar o ensino e aprendizagem, outro modo de lidar com a criança. Para Leal (2006, p. 245) "a infância interroga, por isso é capaz de alterar os rumos dos acontecimentos. Podemos dizer que ela não aceita a previsibilidade, porque sente o mundo de uma maneira dinâmica, bem ao contrário do adulto, para quem o certo é contar com que é sabidamente previsto".

Encarar a concepção de criança, conforme Leal (2006), Kohan (2007) e outros autores nos indicam, vem sendo um desafio para os professores, não só um desafio, mas algo completamente complexo, uma vez que as diversas mudanças necessárias extrapolam o campo educacional, incidindo sobre uma forma de pensar a criança, a infância que foi construída historicamente pela sociedade. Contudo, os docentes percebendo as especificidades da criança na primeira infância sentem-se inseguros quanto ao trabalho com essa faixa etária incorrendo ainda em implicações no trabalho do professor conforme afirma a professora Karen (Entrevista, 03/03/2016):

Muito medo de não dar conta, em certa altura do ano pensei: meu Deus será que vou dar conta? Deixei muito conteúdo para trás por causa do ritmo lento deles, é diferente o ritmo. Geralmente no $1^{\circ}$ ano eu começo o ano aplicando a letra cursiva e no ano passado eu comecei mais ou menos no meio do ano. Alguns conseguiam fazer porque a família, às vezes, ajuda muito em casa, mas outras não. Foi 
muito difícil, muito sofrido, aí eu desisti.

Sabe-se que as crianças estão em processo de desenvolvimento físico, emocional, intelectual, logo, são plenamente capazes de aprender o que Ihes é oferecido, a partir das interações diretas ou indiretas. Entretanto, notase que ainda predomina para as crianças um olhar carregado de incapacidade, ou capacidade, sempre inferior ao adulto.

De acordo com Leite (2011) lidamos com as crianças como se elas fossem seres com potencial limitado de criar, inventar, aprender e ir além do que imaginamos serem capazes, entretanto, não raro nos surpreendemos com as respostas dadas, com as palavras inteligentemente inventadas. Nós, os adultos, admiramo-las exatamente porque elas são naturalmente livres, escapam da vida, do mundo previsível, organizado dos adultos. De encontro a isso Leal pontua que a criança é vista como "iniciante, que não sabe, desprovido de saber, de conhecer, de experiência. Falta-lhe algo, incompleto, carente. Incapaz, inferior, frágil, controlado, dependente" (LEAL, 2006, p. 21).

Trabalhar com crianças exige uma compreensão do seu universo, do seu pensar e do seu fazer, sobre isso Kramer (2006, p. 36) nos aponta que é preciso que as crianças sejam "atendidas nas suas necessidades (a de aprender a de brincar), que o trabalho seja planejado e acompanhado por adultos na Educação Infantil e no Ensino Fundamental e que saibamos em ambos, ver, entender e lidar com as crianças, como crianças e não apenas como estudantes".

A inserção das crianças com 06 e 05 anos mobilizou, provocou ações, estudos, porém há indicações que tais inquietações advêm unicamente das crianças e das professoras que atuam com elas. De acordo com resultados da pesquisa, foram as professoras que sentiram necessidade de mudanças. Podemos observar isso no relato da professora Eva (Entrevista, 08/03/2016) "É difícil dizer, mas não recebi nenhum suporte. "Eu fui em busca, corri atrás e o que eu tentei mudar na minha postura como professora do Ensino Fundamental." Nesse sentido, o Ministério da Educação - MEC (BRASIL, 2004, 
p. 24) orienta:

É essencial que esse professor esteja sintonizado com os aspectos relativos aos cuidados e à educação dessas crianças, seja portador ou esteja receptivo ao conhecimento das diversas dimensões que as constituem no seu aspecto físico, cognitivo-linguístico, emocional, social e afetivo. Nessa perspectiva, é essencial assegurar ao professor programas de formação continuada, privilegiando a especificidade do exercício docente em turmas que atendem a crianças de seis anos.

A orientação do documento diz respeito à inserção da criança de 06 anos, ao pensarmos na atual conjectura educacional a qual insere a criança com 05 anos a completar 06 anos até o dia 31 de dezembro no ensino fundamental, seria essencial que tais orientações se cumprissem. Ainda de acordo com a citação deve-se assegurar a formação continuada do professor para que esse tenha condições de desenvolver um bom trabalho com as crianças pequenas. Dessa forma, há um distanciamento entre o que a legislação propõe e o que realmente encontramos nas escolas de forma geral, uma vez que enquanto crianças somos potência, porém não vem sendo oferecido meios para que isso se efetive.

Ao inserir as crianças de 05 anos de idade, com a justificativa de inclusão e qualidade na educação, corre-se o risco de ofertar para as crianças a mesma escola que foi ofertada por muito tempo às crianças que eram inseridas com 07 anos, e que em alguns lugares do país não se garante as condições mínimas que atendam à criança, à infância em suas especificidades, em suas necessidades humanas. Embora os documentos do MEC orientem que haja uma formação para os professores atuarem no ensino fundamental de 09 anos, os resultados da pesquisa apresentam o contrário.

As professoras tiveram que mudar suas práticas. Entretanto, observamos entre as professoras modos distintos de lidar com a infância, percepções de inquietações que cresceram no tocante a inserção da criança de 05 anos no ensino fundamental, conforme observado no caderno de registro da professora Eva (Caderno de registro, 10/06/2016) que tivermos acesso. 
Já no pátio demos início à atividade, a qual consistia em jogar duas bolitas dentro de uma caixa que estava dividida como uma colmeia e em cada espaço havia números que variavam de 1 a 20 , além de um dado com os símbolos de adição e subtração, o qual deveria ser jogado e a partir dele se determinaria o cálculo a ser feito.

A professora Eva já desenvolvia um trabalho distinto das demais, acreditamos que, entre outras razões, o fato de ela atuar no PIBID contribua para que seu fazer se diferencie dentro do grupo do CBA. A inserção das crianças de 05 anos fez com que ela ampliasse o uso do lúdico em seus planejamentos, a saber: a música, cotação de história com recursos, jogos, material concreto entre outros. Acreditamos que trabalhar com a ludicidade propicia um significado maior aos conteúdos e sentido para as crianças. Por assim dizer, a professora foi levada a ver que este era o melhor jeito de desenvolver os seus trabalhos de forma a tentar realizar atividades que fizessem sentido às crianças, bem como dentro de suas possibilidades.

Nesse sentido, essa prática se constitui em uma perspectiva peculiar de trabalho, como relata a professora Eva (Entrevista, 08/03/2016):

[...] se tratando de 05, 06 anos eles têm menos vivências que o aluno de 07 anos. E o de 05 anos em relação ao de 6 anos menos ainda, então, é preciso a gente se adaptar: na forma de falar, a forma de agir dentro sala, a forma de conduzir o conteúdo, de passá-lo, de explicá-lo. Tudo isso teve que ter uma adaptação, teve que mudar, a professora EVS teve que mudar. Não é que eu não trabalhasse com jogo, não trabalhasse com música, trabalhava sim, mas agora tem que ser com mais ênfase.

As alterações existentes na escola decorrem das transformações que as crianças impõem. Ou como diz Agamben (2007), profanar, todo ou qualquer instrumento e situação em algo com sentido e significado diferente daquele atribuído e esperado pela docente. Ou dito de outra forma, é possível observar o quanto a criança coloca/provoca as professoras a reinventarem-se como professoras. Não é mais do mesmo jeito, a criança "quase te obriga" a ser de outra maneira. A isso, denominamos de invenção. É aquela coisa de nascimentos, recomeços. Se não houver nascimentos não tem vida, se não tem vida, é uma prática morta, ou fadada à morte, à aniquilação.

Outra questão observada nas entrevistas e pela vivência com as 
pequenas, dentre as implicações imposta pelas crianças está o brincar, o qual foi inserido no cotidiano da sala. Como observamos no relato da professora Karen (Entrevista, 03/03/2016):

[...] às vezes a gente até brinca um pouquinho dentro da sala de aula para distrair. Esses dias eles falaram: "vamos brincar professora daquele negócio de esconder o objeto". É uma brincadeira que eu mando um ir lá fora e escondo o objeto aqui dentro da sala, e ele vem procurar, igual detetive, procura aqui, procura ali, está quente, está frio, eles adoram brincar disso e esse ano elas já me cobraram.

A concepção de criança entendida por nós, a concebe como um ser social, de direito, plural, que está inserido em uma cultura de igual modo diversificada, e sobre a qual interfere. Sendo assim, ao pensar a respeito das mudanças que a professora fez em função da inserção das crianças de 05 anos de idade, ao refletir sobre as alterações e desafios que a presença das crianças trouxe para as profissionais, trazemos, por exemplo, o canto da leitura, antes inexistente na sala de aula como podemos verificar a partir da fala da professora Eva (Entrevista, 08/03/2016):

Vendo a necessidade, foi se mudando, foi se inserindo mais jogos, inserindo um cantinho fixo de leitura. Antes eu tinha alguns livros, mas não tinha o cantinho da leitura fixo. Eu tinha uma caixa, a gente trabalhava as atividades e de vez em quando nós parávamos e fazíamos uma roda de leitura.

Sendo assim, a professora em questão foi mudando sua prática pedagógica conforme as necessidades das crianças. Em se tratando de tempo, a escola estabelece o seu horário de forma cronológica, o qual tende a funcionar como modo de controle e disciplina. A esse respeito, os documentos analisados evidenciam que o tempo, o ritmo de aplicação das atividades teve que ser repensado. A partir da necessidade das crianças, forçadamente ou não, as vivências correspondentes à sala de aula foram adaptadas ao tempo e ritmo dos pequenos.

E percebi que com as crianças não adianta ter pressa, não é ao meu tempo, mas sim ao tempo delas, que foi essencial para a assimilação do conteúdo que fossemos parando e conversando com eles. (OLIVEIRA, caderno de Campo, maio, 2016). 
Nessa direção, as professoras entrevistadas mencionaram sobre as mudanças que ocorreram em suas práticas docentes. A professora Eva (entrevista, 08/03/2016): afirma que "É necessário ter um jogo de cintura muito grande, porque são crianças que na idade deles é natural não ficarem muito tempo concentradas em uma só atividade, é preciso diversificar as atividades para eles se sentirem bem." Nessa perspectiva, a infância exige pensar uma temporalidade para além do tempo cronológico da existência humana, das fases da vida e das etapas do desenvolvimento. "A infância tem muito a ver com uma possibilidade de intensificar certa relação com o tempo, de instaurar um outro tempo" (KOHAN, 2007, p. 113).

\section{ALGUMAS CONSIDERAÇÕES}

Neste artigo procuramos refletir sobre a inserção das crianças com 05 anos no ensino fundamental e suas implicações. A partir dos resultados obtidos nesta pesquisa, podemos dizer que antecipar a escolarização das crianças nos provoca a reflexão sobre muitos aspectos, entre eles, destacamos: as questões legais, as de caráter pedagógico, organizacional, infraestrutural e formativo.

A criança ao passar da educação infantil para o ensino fundamental não deixa de ser criança, pois, por vezes nos parece que a escola, deixa de olhá-las como criança, e as enxergam como alunos, isto é, um ser subtraído de toda a sua singularidade, um ser homogêneo que precisa responder única e exatamente o que a escola espera. Compreendemos que a criança tem sim, toda a potencialidade de ser alfabetizada ainda na primeira infância, porém esse processo deve ser pensado a partir da criança, para e com a criança.

Também constatamos que não houve uma reorganização da escola pesquisada para receber as crianças com 06 anos, tão pouco para a inserção das crianças com 05 anos de idade. A escola não oferece flexibilização de tempo e de espaço. Por meio das entrevistas verificou-se que o pouco tempo e espaço que foi oferecido às crianças se deu pelas mudanças provocadas pelas crianças e possibilitadas pelas professoras.

A escola tem funcionado como um aparelho repressivo e opressor 
desde a infância Foucault (2014), isso nos leva a uma reflexão mais ampla sobre a educação: que tipo de escola temos e oferecemos às crianças? Com que olho devemos olhar a infância e a criança? Como garantir o direito à brincadeira em espaços diversificados nas escolas de ensino fundamental?

A escola para todos surgiu em função de uma necessidade da sociedade industrializada, e ao longo dos tempos se manteve dualista e excludente. Logo, as políticas públicas que estão sendo pensadas para a educação, como a que nos dedicamos a analisar nessa pesquisa, leva em consideração apenas interesses particulares, desconsideram aqueles que constroem a escola no dia a dia, ou seja, o sistema educacional brasileiro se encontra nada democrático e rigorosamente hierarquizado. Assim, observamos que existe um abismo entre o que é proposto nas legislações vigentes e o que, realmente, se efetiva na prática escolar, no chão da escola, rompendo de forma brusca a vivência da infância pela qual a criança estava inserida na educação infantil.

A chegada das crianças com 05 anos à escola de ensino fundamental coloca-nos a pensar uma questão que pouco tem se refletido: a infância na escola. Quer dizer, seja na educação infantil ou no ensino fundamental, muitas crianças já estão na escola, antes dos 05 anos de idade. Elas, as crianças na e pela infância, habitam e percorrem esse lugar. Falam outras línguas e outras linguagens muitas vezes ignoradas. Movimentam-se sem sair do lugar, pois seus corpos ativos e vivos são subtraídos, castrados, contidos. Seus pensamentos silenciados, pois o que vale é uma única verdade: a do adulto. Outra questão se coloca aqui: a quais direitos às crianças têm direitos? O direito a uma educação de qualidade, como preconiza a legislação, ou a uma escolarização antecipada e a qualquer custo? Para onde vai o direito a viver a infância, o brincar e a própria vida com dignidade e liberdade? O que estamos fazendo com nossas crianças e com a infância das crianças? A que projeto isso tudo serve?

O que podemos dizer ainda depois do que tanto ouvimos e vivenciamos junto às crianças e às professoras? Podemos dizer junto a elas que tornar-se professora de criança pequena não vem estabelecido em 
manual de instrução, ou em receitas médicas e de cozinha, nem mesmo está escrito nas estrelas, ou seja, não existe uma forma padrão, linear e supostamente infalível de exercer a docência com crianças. O que observamos, são movimentos intensos juntos as crianças de aprender a ser professora, sendo professora, com um olhar sensível, uma escuta atenta, um corpo aberto à infância do mundo e a infância que atravessa as crianças. Infelizmente esse movimento muitas vezes, porque não dizer, quase sempre, acontece de modo muito solitário e doloroso.

\section{REFERÊNCIAS}

AGAMBEN, G. Profanações. São Paulo: Boitempo, 2007.

ARELARO, L. R. G. O ensino fundamental no Brasil: avanços, perplexidades e tendências. Educação e Sociedade, Campinas, v. 26, nº. 92, p. 1039-1066, Especial - out. 2005.

BARBOSA, M. C. S. O ensino obrigatório aos 6 anos e sua ampliação para 9 anos trará vantagens ou não aos alunos? Revista Pátio, p. 50-53, Fev/Abr 2006.

BRASIL. Constituição da Republica Federativa do Brasil: Texto constitucional promulgado em 5 de outubro de 1988. Brasília: Senado Federal Subsecretaria de Edições Técnicas, 1988.

BRASIL. Lei de Diretrizes e Bases da Educação Nacional. Lei n 9.394/96. Brasília: MEC, 1996.

BRASIL. Lei n $n^{\circ}$ 10.172, de 9 de janeiro de 2001. Aprova o Plano Nacional de Educação e dá outras providências. Diário Oficial da União, Brasília, 10 jan. 2001.

BRASIL. Ensino Fundamental de Nove Anos: orientações gerais. Ministério da Educação. Secretaria de Educação Básica, Departamento de Políticas de Educação Infantil e Ensino Fundamental, Coordenação-Geral do Ensino Fundamental. Brasília: SEB/ DPE/COEF. 2004.

BRASIL. Lei n. $11.114,16$ de maio de 2005. Altera os arts. $6^{\circ}, 30,32$ e 87 da Lei n. 9.394, de 20 de dezembro de 1996, com o objetivo de tornar obrigatório o início do ensino fundamental aos seis anos de idade. Diário Oficial da União, Brasília, DF, 17 maio 2005. Disponível em: www.mec.gov.br/cne.

BRASIL. Lei n. 11.274, 6 de fevereiro de 2006. Altera a redação dos arts. 29, 30, 32 e 87 da Lei n. 9.394, de 20 de dezembro de 1996, que estabelece as 
diretrizes e bases para a educação nacional, dispondo sobre a duração de 9 (nove) anos para o ensino fundamental, com matrícula obrigatória a partir dos 6 (seis) anos de idade. Diário Oficial da União, Brasília, DF, 7 fev. 2006.

BRASIL. Ministério da Educação. Conselho Nacional de Educação. Parecer CNE/CEB n. 4/2008. Orientação sobre os três anos iniciais do Ensino Fundamental de nove anos. Disponível em: www.mec.gov.br/cne.

BRASIL. Ministério da Educação. Conselho Nacional de Educação. Câmara de Educação Básica. Resolução n 1, de 14 de janeiro de 2010. Define Diretrizes Operacionais para a implantação do Ensino Fundamental de 9 (nove) anos. Disponível em:

http://portal.mec.gov.br/index.php? option=com_docman\&view=download \&alias=24 83-rceb001-10\&ltemid=30192. Acesso em 12 de set 2016.

BRASIL. Ministério da Educação. Conselho Nacional de Educação. Câmara de Educação Básica. Resolução n 6, de 20 de outubro de 2010. Define Diretrizes Operacionais para a matrícula no Ensino Fundamental e na Educação Infantil. Disponível em:

http://portal.mec.gov.br/index.php?option=com_docman\&view=download \&alias=1515 9-rceb006-10-5\&ltemid=30192. Acesso em 12 de set 2016.

BRASIL, Plano Nacional de Educação. Lei n¹3. 005, de 25/06/2014, Brasília, 2014.

FOUCAULT, M. Vigiar e punir: nascimento da prisão. 42 ed. Petrópolis, RJ: Vozes, 2014.

KRAMER, S. As crianças de 0 a 6 anos nas políticas educacionais no Brasil: educação infantil e/é fundamental? Educação e Sociedade, Campinas, v. 27, n. 96 - Especial, p. 797-818, out. 2006.

KOHAN, W. Infância, estrangeiridade e ignorância. Belo Horizonte. MG: Autêntica, 2007.

KRAMER, S. As crianças de 6 anos nas políticas educacionais no Brasil: educação infantil e/é fundamental. Educ. \& Soc., Campinas, v.27, n.96, p.111, Out. 2006.

LEAL, L. F. Quando a infância ensina - uma leitura interessada de Abril despedaçado. In: TEIXEIRA, I. A. de C.; LARROSA, L. e LOPES, J. de SOUSA. (Orgs.). A infância vai ao cinema. Belo Horizonte: Autêntica, 2006.

LEITE, C. D. P. Infância, experiência e tempo. São Paulo: Cultura Acadêmica, 2011.

LIRA, A. C. M.; MACHADO, A. F. M.; FASSINI, C. C. S. O. Professores e crianças no primeiro ano do ensino fundamental de nove anos: desafios e Expectativas. Revista Contra Pontos. v. 11, n. 2, 2011. 
OLIVEIRA, E. G. de. Caderno de campo: Relatórios diários produzidos durante a permanência como bolsista do Programa Institucional de Bolsa de Iniciação à Docência - PIBID de 10 de março a 15 de dezembro de 2016.

ORLANDI, L. A.; LIMA, J. M. A criança de seis anos no ensino fundamental: produção de conhecimento em teses e dissertações . Nuances: estudos sobre Educação, Presidente Prudente - SP, v. 26, número especial 1, p. 116135, jan. 2015.

RONDÔNIA. Resolução N. 824/2010/CEE/RO. Fixa normas para a matrícula na Educação Infantil e no Ensino Fundamental no sistema estadual de ensino a partir do ano letivo de 2011. Disponível em:

http://www.seduc.ro.gov.br/portal/index. pop/legislacao.html. Acesso em 12 de set de 2016.

RONDÔNIA Autos do processo no 11677-27.2013.4.01.4100 Liminar da idade corte. Dispõe sobre as diretrizes operacionais para a implantação do Ensino Fundamental de 09 (nove) anos. Poder Judiciário Federal, Porto Velho, RO, 10 de dez. 2013.

RECIFE. Autos do processo n 0013466-31.2011.4.05.8300 Liminar da idade corte. Dispõe sobre as diretrizes operacionais para a implantação do Ensino Fundamental de 09 (nove) anos. Poder Judiciário Federal, Recife, PE, 22 de nov. 2011.

SAVELI, E. de L. Ensino Fundamental de nove anos: Bases legais de sua implantação. Práxis Educativa, Ponta Grossa, PR, v. 3, n. 1, p. 67 - 72 jan.-jun. 2008. 